\title{
An Analysis of the Effectiveness of Tutorial Learning Aids in MyMathLab: Part 2
}

\author{
Joan M. Raines (Corresponding author) \\ University Studies Department, Middle Tennessee State University \\ P.O. Box 16, Murfreesboro, TN 37132, United States \\ E-mail: Joan.Raines@mtsu.edu \\ Linda M. Clark \\ University Studies Department, Middle Tennessee State University \\ P.O. Box 16, Murfreesboro, TN 37132, United States \\ E-mail: Linda.Clark@mtsu.edu
}

Received: July 22, 2016

Accepted: August 2, 2016

Published: August 31, 2016

doi:10.5296/gjes.v2i2.9764

URL: http://dx.doi.org/10.5296/gjes.v2i2.9764

\begin{abstract}
The intent of the study was to continue an examination of the learning aids that are available for students to use when completing homework online in MyMathLab and try to determine if these aids improved mathematics learning and achievement in a redesigned elementary algebra course. A quasi-experimental pre/posttest design was employed to investigate data for 225 students enrolled in eleven sections of the course. Comparisons were made among four groups - a control group having access to both learning aids and three experimental groups having access to only one or none of the aids. Based on the findings of the data analysis, the two learning aids "Help Me Solve This" and "View an Example" appeared to have no effect on mathematics learning and student outcomes in the course. However, it did appear that for certain mathematics content, the type of learning aid students had access to made a difference in homework grades.
\end{abstract}

Keywords: MyMathLab, Online homework, Tutorial learning aids, Online course management systems 


\section{Introduction}

Past research has shown that homework can be particularly beneficial and has consistently been regarded as an essential course element (e.g. Cooper, 1994; Cooper, Robinson, \& Patal, 2006; Paschal, Weinstein, \& Walberg, 1984). This is particularly true in mathematics classes. Homework promotes the retention of concepts and skills, and fosters an understanding of the content taught. Thus, students need to and should be provided with the opportunity to practice or review these concepts and skills that are taught in class, with homework assignments. The effectiveness of such assignments to facilitate student learning, and the relationship between doing homework and academic achievement in mathematics has been acknowledged in several studies (Bruce \& Singh, 1996; Cartledge \& Sasser, 1981; Walberg, Paschal, \& Weinstein, 1985). Thus, the value in assigning homework in mathematics is obvious.

Finding new ways to enhance learning and help students succeed in math is at the forefront of higher education. The use of textbook-based course management systems has become fairly widespread, and online homework is getting to be a significant component in college mathematics courses. These systems offer improved learning outcomes and many of them include some type of learning aids to help students in completing their assignments. This study focuses on specific learning aids that are available in one such course management system, MyMathLab, and how these aids might affect student outcomes in a redesigned elementary algebra course.

\section{Review of Literature}

In a review of the literature, studies were found that examined the use of textbook and web-based course management systems to complete homework online. Additionally, some studies explored students' perceptions of these systems along with the effects of doing online homework on students' mathematics learning. Although some of the research on the effectiveness of these online homework systems revealed mixed results, many others concluded students do derive multiple benefits from completing homework online. Furthermore, they found that students performed just as well, if not better, when doing homework online compared with traditional homework.

For example, Hirsch and Weibel (2003) investigated the effects of using WeBWork, an internet-based homework system, on student performance in general calculus classes at Rutgers University. Of the 1,175 students in the study, 368 were in the control group and completed written homework assignments only. The experimental group consisted of 807 students who completed the same written homework except some of their written problems were replaced with questions in WeBWork. Hirsch and Weibel found that the students in the experimental group doing web-based homework had "a small but statistically significant improvement (of 4\%)" on the final exam for the course ( $\mathrm{p} 14$ ). Their results suggested a quadratic relationship existed between the percentage of web-based homework problems attempted and the final exam grade, which indicated that students who completed less than $50 \%$ of the web-based homework received negligible benefit on the final exam. Zerr (2007) also found that students benefited from doing homework online when he conducted a study using both quantitative and qualitative data to analyze the effects of online homework in a 
first semester calculus class at the University of North Dakota. Students in the control group $(n=23)$ were given paper and pencil assignments that were not graded and the option to complete the online homework assignments. Students in the experimental group $(n=27)$ were required to do homework online. He compared student outcomes on quizzes and exams and found students' learning was improved with the use of the online homework system. Zerr also indicated, from survey data, that students' attitudes toward the online homework were positive and thus increased student engagement.

In order to determine if students who completed homework using MyMathLab would have increased academic performance over students who did traditional paper graded homework, Kodippili and Senaratne (2008) completed a study at Fayetteville State University involving 72 students in four sections of a college algebra course. Two different instructors who were experienced in using MyMathLab taught these sections. After analyzing the data, a t-test revealed there was no significant difference in students' achievement in college algebra between the two groups of students. However, students' success rates as measured by the percentage of final grades were significantly higher for those using MyMathLab for homework (70\%) than for students doing traditional paper homework (49\%). Likewise, Brewer and Becker's (2010) study examined the effects of online homework compared to traditional homework in a college algebra course at a large, western community college. Their sample consisted of 145 students enrolled in nine sections of the algebra course. Four of the sections formed the treatment group $(\mathrm{n}=60)$ which completed homework online and the other five sections $(n=85)$ formed the control group which completed traditional textbook-based homework. Problems on homework assignments for the two groups were similar in length, degree of difficulty and type of problem. After examining final exam scores based on the groups, Brewer and Becker found that those students who completed homework online had higher exam grades in general; however, there was no significant difference in the mathematics achievement between the two groups. The researchers concluded that using online homework for college algebra would be an effective learning tool. Burch and Kuo (2010) completed a similar study using college algebra classes at Indiana University of Pennsylvania. They compared test scores of students in three sections of the course who did traditional paper and pencil homework with test scores of students in two sections of the course who used an online homework system. Burch and Kuo found that the students doing online homework had higher test scores than their counterparts, and the difference in the mean test scores for the two groups of students was statistically significant. Conversely, there was no significant difference in the final exam grades for these students. The researchers did note that students in the sections completing online homework had much higher retention rates $(86 \%)$ than those in the paper homework sections $(58 \%)$. Taking these findings into consideration, Burch and Kuo inferred that using the online homework system would be beneficial. Babaali and Gonzalez (2013) also supported using an online homework system over traditional paper and pencil homework. Their study explored the effects on student performance of the use of an online homework system in an entry-level pre-calculus course at York College. Final exam data was obtained from students registered in eight sections of the course. The control group consisted of four sections of the course with 122 students who completed traditional paper and pencil homework assignments. The other four sections of 99 
students comprised the experimental group who used the software Hawkes Learning Systems to complete homework online. The researchers stated that the students in the experimental group not only had better success on the final exam, but also had an average grade on the exam that was about fifteen points higher than the average grade for the control group. The average grade for the experimental group was statistically significantly higher than in the control group $(\mathrm{p}=0.00003)$. Babaali and Gonzalez indicated that the students in the experimental group benefited from doing homework online because the students spent more time doing homework and did more problems than students in the control group.

Along with the previously mentioned studies, others have also assessed the mathematics learning and achievement of students who used some type of course management system to complete homework online; however, these students were not prepared for college-level mathematics and required some type of remediation.

For example, at Onondaga Community College, a comparison was made of students taking beginning and intermediate algebra online with students taking the classes in a traditional on campus setting. Results revealed that the passing rate on the departmental final exam was higher for the online students, who used an online courseware system to complete homework, than for the traditional students (Testone, 2005). After reviewing these results, faculty at the college decided this difference might have been related to the online students having access to and using the online system, so it was made available for all students to use. Students who chose to use the system and complete homework online had greater success rates than their counterparts, and the developmental math instructors felt this success was related to the use of the system and its interactive homework tutorials. In an effort to determine the effect of doing homework online for students who were underprepared for college-level math, Baker and Dias (2008) conducted a study at Hostos Community College. Students in the study were enrolled in elementary algebra classes taught by the two researchers who used the pass rates of the exit exam to measure the effectiveness of the web-based software they introduced as a supplement for homework. The control group $(n=134)$ consisted of classes previously taught by the researchers where students completed traditional paper and pencil homework. The experimental group $(n=80)$ consisted of classes the researchers taught using an online textbook-based course management system to complete homework. Both researchers reported a statistically significant $(\mathrm{p}<0.01)$ improvement in the pass rate for students in the experimental group. Baker and Dias stated that student learning was enhanced by the use of web-based homework. Likewise, in her study at the Owens campus of Delaware Technical and Community College, Vezmar (2011) examined how MyMathLab effected student achievement in elementary algebra classes. The final sample consisted of 178 students who completed all elements of the course, with $54 \%$ of these students having had previous experience using MyMathLab. Results of the data analysis showed the online system had a significant effect on student achievement as measured by final exam scores, and a t-test revealed there was a statistically significant increase in average final exam grades for students who had homework grades that were $75 \%$ or higher. Additionally, there was a statistically significant correlation between homework grades and final exam grades. Vezmar 
felt there was enough evidence to state that MyMathLab did facilitate and improve student achievement.

Very few studies have looked at the specific components of the various online courseware systems. Studies that have been done were mainly qualitative in nature, and most used survey data to better understand students' perceptions relating to the use of such systems and of completing homework online. Several of these studies examined one online homework system in particular, MyMathLab, and the various components of the courseware that were available. It has been found through the use of survey data that a majority of students using MyMathLab felt they had a better and increased understanding of the math concepts after using the courseware to complete homework, it helped them achieve a higher grade in their course, it helped them perform better on their assignments, and the time they spent working on homework assignments was beneficial to them (Buzzetto-More \& Ukoha, 2009; Holt, Holt, \& Lumadue, 2012; Law, Sek, Ng, Goh, \& Tay, 2012; Speckler, 2012). In the study conducted by Holt, Holt, and Lumadue (2012), survey respondents were asked to rank which features of MyMathLab they found useful. The two features respondents felt were the most beneficial to them were "Help Me Solve This" (67\%) and "View an Example" (66\%). Likewise, Vezmar (2011) and Speckler (2012) also noted that a majority of students responding to survey items reported the most beneficial and commonly used features of MyMathLab was one of the learning aids, either "Help Me Solve This" or "View an Example". Overall, students felt the learning aids helped them persevere and not become discouraged, and perceived the system to have a positive impact on their mathematics understanding.

In an earlier study, Raines and Clark (2013) examined data to try to determine if the tutorial learning aids in MyMathLab, specifically "Help Me Solve This" and "View an Example", improved mathematics learning and achievement in a redesigned elementary algebra course. The researchers taught two sections each of the course during the fall 2012 semester. All students taking the course used MyMathLab to complete homework online. The control group $(n=39)$ for the study consisted of those students who completed homework online using both learning aids while the experimental group $(n=45)$ had access to "View an Example" only when completing homework. Results of the data analysis revealed there were no statistical significant differences between the two groups, so neither of the learning aids had an effect on mathematics learning and overall performance in the course. The learning aids students had access to during the study had no significant effects on student outcomes in the course.

In this follow up to the previous study, the researchers examined changing students' access to which learning aid, if any, they could use when completing homework online.

\section{MyMathLab}

MyMathLab is an online textbook-based course management system, is customizable, and was developed by Pearson Education. It was used concurrently with the required textbook for the course. In order to register and subsequently access the system, students must purchase an access code and use a course ID provided by their instructor. MyMathLab contains a multimedia e-text, video lectures, computational examples, animations, interactive tutorials, 


\section{Macrothink}

Global Journal of Educational Studies

ISSN 2377-3936

2016, Vol. 2, No. 2

practice exercises, and sample quizzes and tests, and can be used 24 hours a day from any computer that has an internet connection. Instructors are able to create homework assignments from an online exercise bank that correlates to textbook problems. Because the questions are algorithmically generated, unlimited practice and mastery of material can occur.

One of the benefits of using a course management system like MyMathLab is that students receive immediate feedback after working a problem. Students are informed if the problem is correct and receive encouraging remarks such as "Excellent!" or "Fantastic!". MyMathLab also informs students when they do not have the correct solution and provides some type of instructional hint as to what they did wrong based on their answer so they can learn from their mistakes (see Figure 1).

Find the slope-intercept equation of the line that has the given characteristics.

$$
\text { Slope }-\frac{9}{5} \text { and } y \text {-intercept }(0,-3)
$$

The slope-intercept equation is $y=\frac{-9}{5} x+3$.

(Type an equation. Type your answer in slope-intercept form. Use integers or fractions for any numbers in the equation. Simplify your answer.)

\section{Sorry, that's not correct.}

The slope-intercept equation of $a$ line is $y=m x+b$, where $m$ is the slope and $(0, b)$ is the y-intercept.

Figure 1. Screen shot of hint given for an incorrect solution from Pearson Education's MyMathLab

Note. Problem from Elementary and Intermediate Algebra: Graphs and Models (4th ed.), by M.L. Bittinger, D.J. Ellenbogen, and B.L. Johnson. Copyright 2012 by Pearson Education, Inc. Reprinted with permission.

Students are limited to three attempts to correctly solve a problem, unless the instructor changes that number. If a problem is incorrect after the third attempt, the correct solution is shown and students then have the option of working a similar problem. This allows students to continue working on problems until they completely understand and master the concept. However, by being able to work problems until they are correct, students might just be guessing until they get a correct solution for the problem. If a student decides to work a problem again, they would get the same type of question, difficulty level, and scope of problem as the original one they worked. 


\section{Macrothink}

Global Journal of Educational Studies

ISSN 2377-3936

2016, Vol. 2, No. 2

Along with the immediate feedback students receive, there are several learning aids available for students to access. Students can email their instructor for help, be directed to pages in the textbook where a similar problem is explained, have MyMathLab show them how to work the problem ("Help Me Solve This"), see an example of a similar problem worked out step by step ("View an Example"), and, for some problems, view a short video or animation explaining how to work a similar problem. This study examined the effect of two of those learning aids specifically, "Help Me Solve This" and "View an Example", on mathematics learning and achievement for students in Essentials of Mathematics.

When students use "Help Me Solve This", the problem they are working on remains on the page and another window opens (see Figure 2). They are then walked through this problem step by step, prompted to answer questions along the way. Once the student completes this tutorial and sees how to completely work through the problem, they can no longer work the same problem and are given a new, similar problem to work on their own. Figure 3 shows the "View an Example" feature, which presents students with the completely worked out solution to an example problem similar to the one they are attempting to solve. Once they have finished reviewing the example problem, students can continue to work on their original problem and they will receive credit once the solution to the problem is correct.

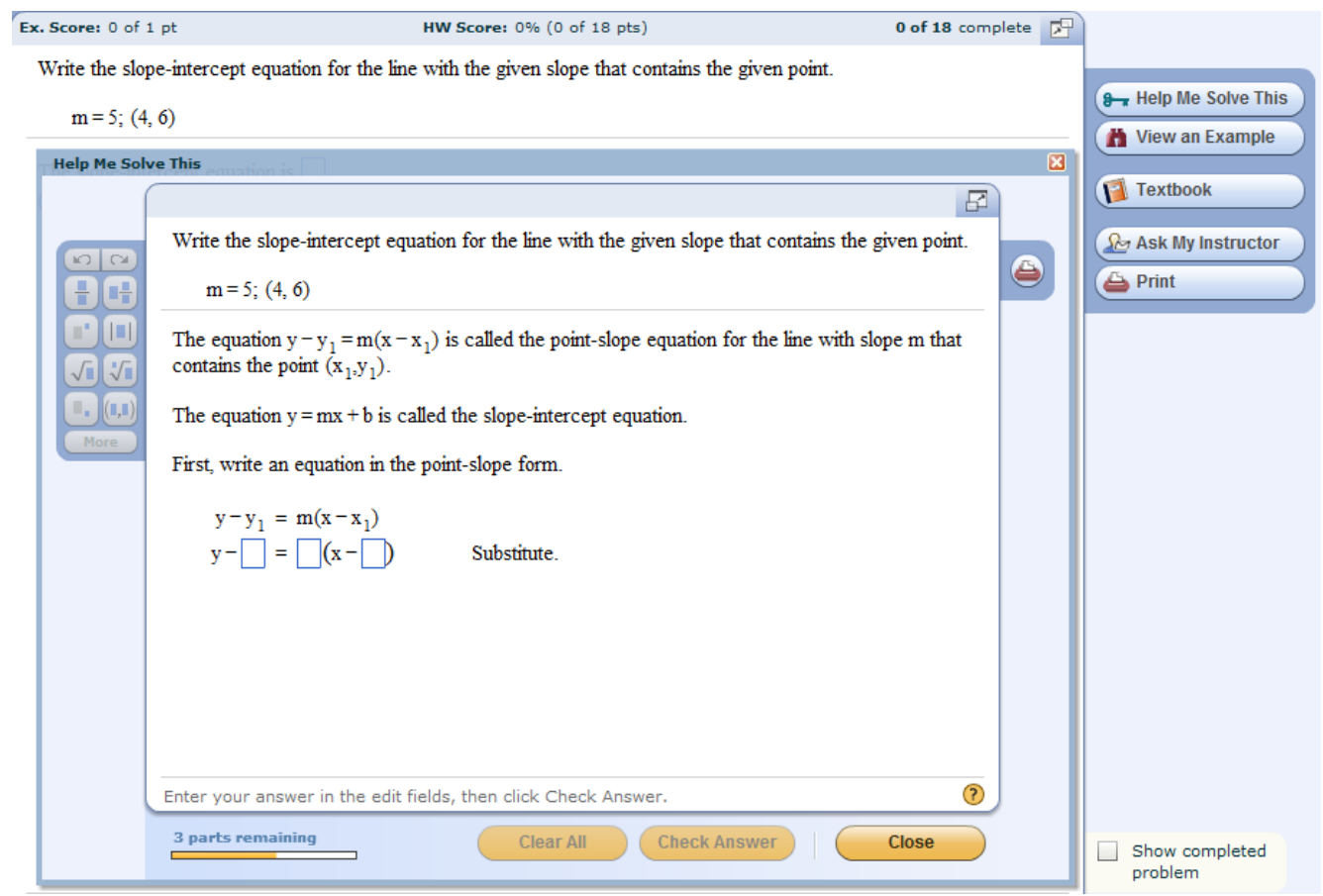

Figure 2. Screenshot of a sample problem using "Help Me Solve This" from Pearson Education's MyMathLab

Note. Problem from Elementary and Intermediate Algebra: Graphs and Models (4th ed.). by M.L. Bittinger, D.J. Ellenbogen, and B.L. Johnson. Copyright 2012 by Pearson Education, Inc. Reprinted with permission. 


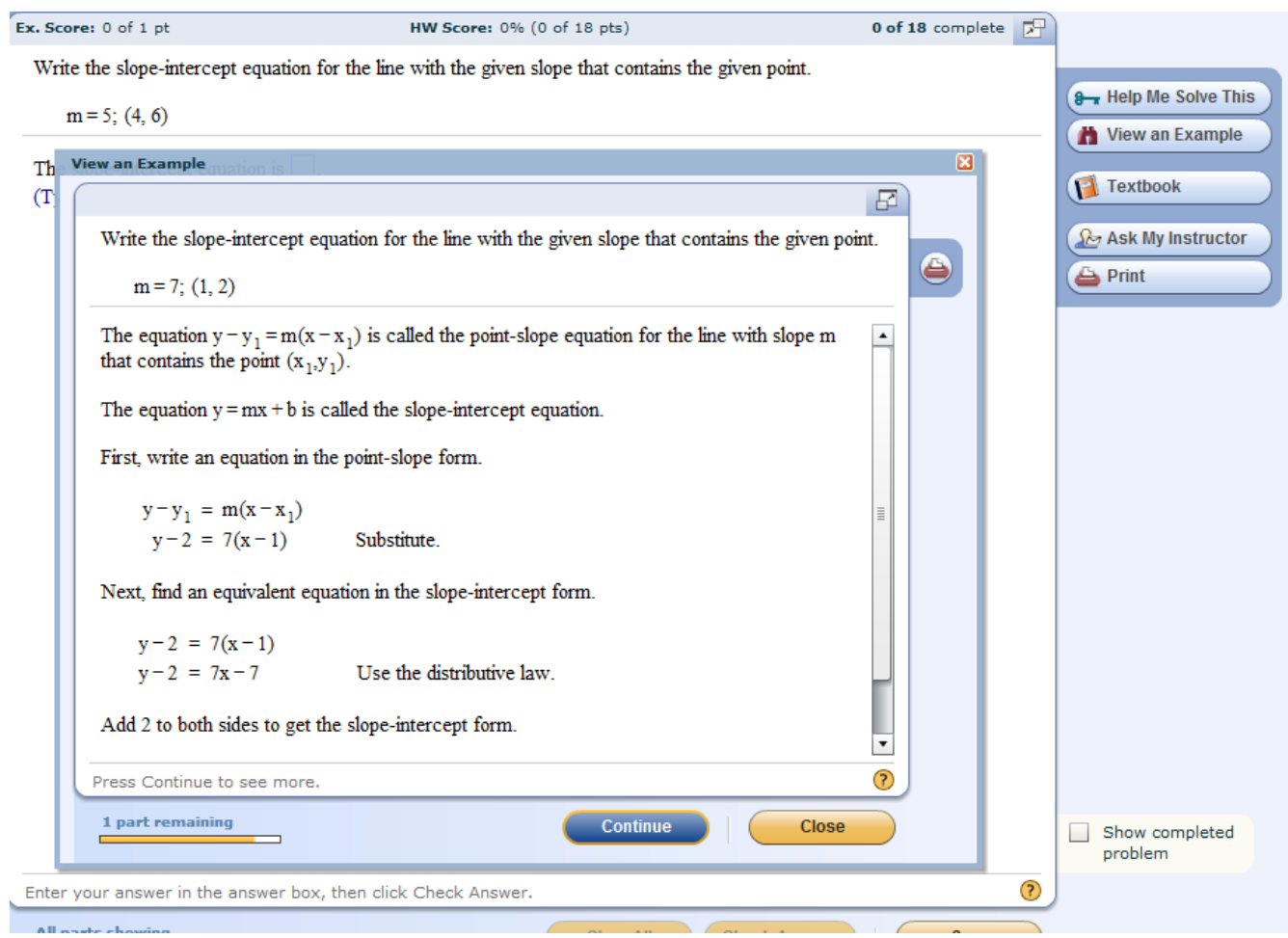

Figure 3. Screenshot of a sample problem using "View an Example" from Pearson Education's MyMathLab

Note. Problem from Elementary and Intermediate Algebra: Graphs and Models (4th ed.). by M. L. Bittinger, D. J. Ellenbogen, and B. L. Johnson. Copyright 2012 by Pearson Education, Inc. Reprinted with permission.

\section{Purpose}

In the first phase of this study, the researchers examined whether using some of the learning aids when completing homework online using MyMathLab affected mathematics learning and/or achievement of students in a redesigned elementary algebra course (Raines \& Clark, 2013). That study compared students who had access to both learning aids "Help Me Solve This" and "View an Example" with students who had access to "View an Example" only. After an analysis of the data revealed there were no significant differences between the two groups of students, the researchers began the next phase of the study to investigate if one or more of these specific learning aids would make a difference in students' learning and subsequent achievement in the Essentials of Mathematics course. Therefore, the purpose of this quantitative study was to determine if having access to and using specific tutorial learning aids when completing homework online using MyMathLab improved students' mathematics learning and achievement. The following research questions were used to guide the study:

1). Do tutorial learning aids make a difference in students' unit homework grades?

2). Do tutorial learning aids make a difference in students' mathematics learning on unit tests? 
3). Do tutorial learning aids make a difference in students' overall performance in Essentials of Mathematics as measured by posttest scores?

4). Is there a pre/posttest difference among students who had access to all learning aids versus those whose access was limited?

\section{Research Methodology}

\subsection{Setting}

This study was conducted at a four-year public university located in the central southeastern United States. The total enrollment at the university for fall 2012 was 25,394 students and 23,881 in fall 2013. In the fall of 2012, 5,486 of those enrolled were freshmen and in the fall of 2013, there were 5,167 freshmen. The average overall ACT composite score at the university in fall 2012 was 21.8 and in fall 2013 was 21.9 with average mathematics test subscores of 20.3 and 20.6 respectively. There were 240 freshmen (8.16\%) with math subscores between 11 and 15, and 1,401 (47.65\%) freshmen with math subscores between 16 and 20 for the fall 2012 semester. These numbers decreased the following fall with 187 freshmen (6.24\%) having math subscores between 11 and 15, and 1,373 freshmen (45.83\%) with math subscores between 16 and 20 . For both fall semesters, approximately $46 \%$ of the population was male and $54 \%$ female.

\subsection{Course}

The mathematics course used in this study was Essentials of Mathematics, a redesigned elementary algebra course that was three credit-hours for which students received elective credit. The course was the first in a two-semester sequence and served as an introduction to learning mathematics at the university level and helping students acquire the foundations and skills necessary to be successful in college-level mathematics. Students were required to take the course if they had not met the university's criteria for enrolling in college-level credit mathematics courses and if their ACT mathematics subscores were 15 or 16, or if additional placement testing scores, required for some students, placed them in the course.

\subsection{Participants}

The participants in this study consisted of students enrolled in eleven sections of Essentials of Mathematics $(\mathrm{N}=252)$ during fall 2012 and fall 2013 semesters. Students at the university self-register for courses which made random assignment to the control group or any of the experimental groups impossible. The final sample for the study, which consisted of 140 females and 85 males, included only those students who completed the course $(n=225)$ and took the departmental final exam used in the analysis of data. The students taking Essentials of Mathematics consisted of both traditional students, generally those students entering college right after graduating high school, and non-traditional students, defined as those students who have delayed attending college, are either full time or part-time, and usually over 23 years old.

Since the course management system MyMathLab is a required component for all sections of Essentials of Mathematics, the students in the study used it to complete homework online. All 
students received similar instruction through traditional lecture in the classroom, completed similar homework, had access to the same unit test reviews and practice tests, and took the same unit tests, pretest and posttest (course final exam).

\subsection{Approach}

The institution typically offered about 30 sections of Essentials of Mathematics during the fall semesters, with a maximum of approximately 25 students each. Students are strongly encouraged to consult with an advisor before registering for classes; however, they can choose to enroll in any section of the course they prefer through the university's registration system. Thus, it was not possible to randomly assign participants to the control group or any of the experimental groups. Therefore, this study used a quasi-experimental, pre/posttest design to answer the research questions.

Two different instructors taught eleven sections of Essentials of Mathematics during the fall 2012 and fall 2013 semesters. All sections of the course for this study were face-to-face lecture-based classes meeting three contact hours a week with all homework assignments completed online. The control group $(n=56)$ consisted of those students who had access to both of the learning aids, "Help Me Solve This" and "View an Example", when completing the homework. There were three experimental groups. The first experimental group $(n=45)$ had access to "View an Example" only, the second group $(n=59)$ had access to "Help Me Solve This" only, and the third group $(n=65)$ did not have access to either of these learning aids.

There were a total of 24 online homework assignments and the number of questions per assignment ranged between 10 and 30 . The homework assignments were similarly aligned, and the questions on each assignment were a mixture of multiple choice and free response questions. The two instructors of the sections of the course in the study constructed the unit tests. The content on these tests matched the objectives of the course and were a mixture of multiple choice and free response questions, with each test consisting of 20-25 questions. Since the sections of the course used in this study met at different times on different days of the week during each semester, the instructors gave the unit tests the same weeks of the semester for each of the two fall semesters. Mathematics learning (did students acquire new knowledge from the material in each unit) was defined as the scores on these unit tests. The final exam was a two-hour test that contained 40 multiple choice questions with four answer choices each. The final was a common departmental exam given to all students taking Essentials of Mathematics and was developed by a committee of faculty in the department to match the objectives of the course, which provided face validity for the exam. Additionally, the exam was reviewed by faculty teaching the course to ensure the exam questions assessed defined course content, which provided content validity; however, it was not reviewed for reliability. The posttest used in the study was a modified version of the final exam. In order to make pre/post comparisons, the posttest had to align with the pretest. Thus, the posttest consisted of the same number and type of questions as the pretest. The pretest was a 45-minute test that consisted of 30 multiple choice questions with four answer choices each. These questions were aligned with the objectives of the course and were of the same type, 
scope, and difficulty as questions on the final exam. This provided face validity for the exam but it was not reviewed for content validity or reliability.

\section{Data Analysis}

A pretest to measure students' prior mathematics knowledge was given on the second day of class to ensure the different groups were homogenous. Results of a one-way ANOVA for the pretest data revealed there were no statistically significant differences in the mathematical ability of the students between the groups $(\mathrm{F}(3,221)=0.38, \mathrm{p}=0.766)$.

Means and standard deviations for unit homework, unit test grades, pretest scores, and posttest scores are shown in Table 1. Data on students who did not complete the course and take the final exam were omitted. The control group (C) consisted of those students who had access to both "Help Me Solve This" and "View an Example" when completing their homework, experimental group 1 (E1) were the students who had access to "View an Example" only, experimental group 2 (E2) had access to "Help Me Solve This" only, and experimental group 3 (E3) did not have access to either of those two learning aids.

Table 1. Pretest, posttest, homework and test averages by group

\begin{tabular}{rcccc}
\hline & Control & Experimental 1 & Experimental 2 & Experimental 3 \\
\hline Unit 1 & & & & \\
HW & $88.11(20.85)$ & $94.23(10.03)$ & $93.87(10.12)$ & $89.66(14.61)$ \\
Test & $75.63(15.17)$ & $77.02(16.80)$ & $78.48(17.40)$ & $73.43(17.03)$ \\
Unit 2 & & & & \\
HW & $78.44(26.72)$ & $84.73(18.63)$ & $90.37(16.35)$ & $78.15(26.83)$ \\
Test & $73.20(15.54)$ & $72.67(13.47)$ & $74.79(18.87)$ & $69.10(17.08)$ \\
Unit 3 & & & & \\
HW & $80.22(24.24)$ & $86.22(21.82)$ & $87.27(17.47)$ & $80.41(26.13)$ \\
Test & $67.75(22.21)$ & $68.02(20.33)$ & $75.19(18.33)$ & $71.02(15.04)$ \\
Unit 4 & & & & \\
HW & $81.49(26.85)$ & $89.29(17.60)$ & $87.43(23.16)$ & $82.09(28.75)$ \\
Test & $77.16(16.82)$ & $79.84(17.40)$ & $80.46(16.56)$ & $84.69(61.88)$ \\
Unit 5 & & & & \\
HW & $82.73(19.28)$ & $82.64(25.59)$ & $74.96(34.46)$ & $75.27(33.30)$ \\
Test & $63.18(17.92)$ & $66.66(20.76)$ & $69.38(21.84)$ & $62.05(23.01)$ \\
Pretest & $33.72(12.12)$ & $32.62(10.52)$ & $34.99(13.39)$ & $33.29(11.05)$ \\
Posttest & $62.45(18.22)$ & $68.01(17.69)$ & $68.07(16.56)$ & $60.10(18.82)$ \\
\hline
\end{tabular}

Note. Standard deviations are in parentheses.

Comparing the means of the unit homework and tests, E1 and E2 had higher homework averages on all homework units with the exception of unit 5. This might appear to suggest that these groups would also have higher test grades on the first four units; but, this was not necessarily the case. Correlations were computed between homework and test averages for the groups (see Table 2). There were low to moderate positive correlations between 
homework and test averages in all cases with the exception of unit 4 for group E3. For all of the units except unit 5, the correlations were significant for some, but not all of, the groups. Examining these values, the correlation between homework and test averages for unit 3 was significant for all groups. This would appear to suggest that for this content and unit, students with higher homework grades tended to have higher test grades, and those students who had access to "View an Example" only appeared to perform slightly better than students in the other groups. For unit 5, none of the correlations were statistically significant suggesting there was not a meaningful relationship between homework and test averages for any group. However, there are other factors which could affect these outcomes. Some students did not complete homework yet had high test scores. These students may have decided to work on test reviews and practice exams in order to prepare for the unit tests instead of completing the homework. Other students had high homework scores and low test grades, which seem to suggest these students may have been receiving too much assistance with their homework either from the learning aids in MyMathLab or from friends or tutors. Allowing multiple attempts on homework questions so as not to penalize students for the learning process also may have been a contributing factor for some high homework scores.

Table 2. Correlations between homework and test averages by group

\begin{tabular}{ccccc}
\hline Unit & C & E1 & E2 & E3 \\
\hline 1 & 0.333 & 0.346 & 0.445 & 0.041 \\
& 0.012 & 0.019 & 0.0003 & 0.749 \\
2 & 0.043 & 0.410 & 0.097 & 0.374 \\
& 0.755 & 0.005 & 0.465 & 0.002 \\
3 & 0.341 & 0.636 & 0.349 & 0.372 \\
& 0.010 & $<0.0001$ & 0.006 & 0.002 \\
4 & 0.102 & 0.534 & 0.407 & -0.271 \\
& 0.456 & 0.0001 & 0.001 & 0.029 \\
5 & 0.226 & 0.226 & 0.137 & 0.239 \\
& 0.094 & 0.136 & 0.301 & 0.055 \\
\hline
\end{tabular}

Note. Cell contents are Pearson correlation, p-value.

After verifying assumptions for analysis of variance were met, one-way ANOVAs and post hoc tests were performed to determine if specific learning aids made a difference in students' unit homework grades, students' mathematics learning as measured by unit tests, and students' mathematics understanding in the course as measured by posttest scores. Additionally, a one-way ANOVA was run in order to compare differences in the overall gain in student learning using the differences between the pretest and posttest scores for the groups. An alpha $=.05$ level of significance was used throughout the study.

\section{Results and Discussion}

This study examined the effects of having access to and using specific tutorial learning aids when completing homework online using MyMathLab on students' mathematics learning and 
achievement. Four research questions were investigated, with null hypotheses as follows:

1). There is no significant difference in the unit homework averages of students having access to either one, two or no tutorial learning aids when completing homework online.

2). There is no significant difference in students' mathematics learning for students having access to either one, two or no tutorial learning aids when completing homework online.

3). There is no significant difference in students' overall performance in Essentials of Mathematics for students having access to either one, two or no tutorial learning aids when completing homework online.

4). There is no significant difference in the overall gain between the pretest and posttest scores for students having access to either one, two or no tutorial learning aids when completing homework online.

To determine whether tutorial learning aids made a difference in students' unit homework grades, one-way ANOVA's were run and a significant effect for unit 2 homework was found $(\mathrm{F}(3,221)=3.82, \mathrm{p}=0.011)$. Tukey's post hoc revealed the mean score for $\mathrm{E} 2 \quad(\mathrm{M}=90.37$, $\mathrm{SD}=16.35)$ was significantly different than $\mathrm{C}(\mathrm{M}=78.44, \mathrm{SD}=26.72)$ and the mean score for E2 was significantly different than E3 ( $M=78.15, \mathrm{SD}=26.82)$. This analysis indicated that the students who had access to "Help Me Solve This" only had significantly higher scores on homework than either students with access to both "Help Me Solve This" and "View an Example" or students who did not have access to either of these learning aids. There were no significant differences between any other groups and no significant effects for any other homework units. Taken together, these results suggest that for specific homework sections, the type of learning aid(s) used does make a difference and has an effect on homework grades.

The second research question addressed whether tutorial learning aids made a difference in students' mathematics learning as measured by unit tests. One-way ANOVA's were completed and no significant effects were found. Thus, no statistically significant differences exist in unit test scores between the groups of students. The results suggest that the specific learning aids used when completing homework online have no effect on test scores. It appears that whether students have one, two or no learning aids available when completing homework, it does not impact their mathematics learning as measured by test grades.

A one-way ANOVA was performed to determine whether tutorial learning aids made a difference in students' overall performance in the course as measured by posttest scores and a significant effect was found $(\mathrm{F}(3,221)=2.92, \mathrm{p}=0.035)$. However, post hoc analyses did not reveal any statistically significant differences in the posttest scores between the different groups of students. These results suggest that the specific learning aids used in this study made no difference in students' mathematics comprehension and retention of the course material in Essentials of Mathematics.

The final research question examined the difference between the pretest and posttest scores for students in the four groups. To determine whether there was a difference in overall gain as 
measured by the difference between the pretest and posttest scores for these students, a one-way ANOVA was run $(\mathrm{F}(3,221)=2.318, \mathrm{p}=0.076)$. There were no significant effects found; thus, there was no statistically significant difference between the pretest and posttest scores. These results suggest that the type of learning aids students used when completing homework online had no effect on the measure of student learning in the course.

\section{Limitations}

There were several limitations involved with this study. The findings may have limited generalizability since the results were based on data drawn from a single institution and focused solely on students in one course, Essentials of Mathematics. The class sections of the course involved in this study met at different times and on different days of the week; thus, there could be differences due to the time of day each class met and the amount of time students spent in each class meeting. Another limitation is that homework grades may not align with actual student learning. Since homework was done outside of class, some students could have gone to math tutoring for assistance or could have received help from friends instead of using any of the system's learning aids. Moreover, there is no way to track if students did use any learning aids and for the control group, which ones. Finally, performance on unit tests was used to measure mathematics learning and posttest scores were used to measure overall performance in the course. It is possible that students benefited from using learning aids in ways not measured by these tests.

\section{Conclusion}

The purpose of this study was to continue an examination of the tutorial learning aids available for students to use when completing homework online in MyMathLab and try to determine if these aids improved mathematics learning and achievement in a redesigned elementary algebra course. To address this issue, four research questions were proposed to guide the study and data were collected during the fall 2012 and 2013 semesters.

Based on the findings, the learning aids "Help Me Solve This" and "View an Example" appear to have no effect on mathematics learning and student outcomes in the course Essentials of Mathematics. It seems that students do just as well in the course overall if they had access to both learning aids, only one of the aids or neither of the learning aids. It did appear that for certain content in the course, the type of learning aid students had access to made a difference in homework grades. Students who had access to "Help Me Solve This" only had significantly higher scores on the second unit of homework than students who had access to either both learning aids or neither of the learning aids. Being able to tell which students used the learning aids, on what problem(s) the aids were used, and the type of learning aid used would possibly reveal more insight into why these students had higher scores. However, that is currently a problem with MyMathLab. Instructors are not able to determine if students are using any learning aids and if so, which ones. If this problem is resolved, future research should include an analysis of how students are using the learning aids - which ones, on what type of problems, how often, etc.

Correlations between homework and test grades also revealed that for certain course content, 
students with higher homework grades tended to have higher test grades. This seems to be the logical conclusion and makes sense. Practice is an important factor in learning and the more practice that occurs, the better a student becomes which is reflected in the learning and retention of course material. However, correlations were not necessarily strong and significant across the board. In some instances, students had high homework grades and low test scores. This seems to suggest that some students might have received too much help with their homework and could have over relied on the learning aids in MyMathLab. Consequently, the use of the tutorial learning aids may need to be limited. Since the use of textbook and web-based course management systems has become so widespread, it is important to examine how they are used and analyze the effects they can have on student learning and achievement.

\section{References}

Babaali, P., \& Gonzalez, L. (2015). A quantitative analysis of the relationship between an online homework system and student achievement in pre-calculus. International Journal of Mathematical Education in Science and Technology, 46(5), 687-699. http://dx.doi.org/10.1080/0020739x.2014.997318

Baker, W., \& Dias, O. (2008). The effect of supplemental web-assisted exercises on student performance in remedial algebra. Mathematics Teaching-Research Journal, 2(3), 27-40.

Brewer, D. S., \& Becker, K. (2010). Online homework effectiveness for underprepared and repeating college algebra students. Journal of Computers in Mathematics and Science Teaching, 29(4), 353-371.

Bruce, F. A., \& Singh, K. (1996). Academic achievement: A model of school learning for eighth grade students. Research in Middle Level Education Quarterly, 19(3), 95-111. http://dx.doi.org/10.1080/10848959.1996.11670076

Burch, K. J., \& Kuo, Y. (2010). Traditional vs. online homework in college algebra. Mathematics and Computer Education, 44(1), 53-63.

Buzzetto-More, N., \& Ukoha, O. (2009). The efficacy of a web-based instruction and remediation program on student learning. Issues in Informing Science and Information Technology, 6, 285-298.

Cartledge, C. M., \& Sasser, J. E. (1981). The effect of homework assignments on the mathematics achievement of college students in freshman algebra. Retrieved from ERIC database. (ED206495)

Cooper, H. (1994). Homework research and policy: A review of literature. Retrieved from http://www.hisparks.com/MathHelpers/Homework_Research_and_Policy.pdf

Cooper, H., Robinson, J. C., \& Patall, E. A. (2006). Does homework improve academic achievement? A synthesis of research, 1987-2003. Review of Educational Research, 76, 1-62. http://dx.doi.org/10.3102/00346543076001001

Hirsch, L., \& Weibel, C. (2003). Statistical evidence that web-based homework helps. FOCUS: Newsletter of the Mathematical Association of America, 23(2), 14. 


\section{I Macrothink}

Global Journal of Educational Studies ISSN 2377-3936 2016, Vol. 2, No. 2

Holt, D., Holt, W., \& Lumadue, R. (2012). At cross-purposes with a developmental mathematics course: Perceptions of students on the use of MyMathLab. Focus on Colleges, Universities, and Schools, 6(1), 1-26.

Kodippili, A., \& Senaratne, D. (2008). Is computer-generated interactive mathematics homework more effective than traditional instructor-graded homework? British Journal of Educational Technology, 39(5), 928-932. http://dx.doi.org/10.1111/j.1467-8535.2007.00794.x

Law, C. Y., Sek, Y. W., Ng, L. N., Goh, W. W., \& Tay, C. L. (2012). Students' perceptions of MyMathLab as an online learning tool. International Journal of e-Education, e-Business, e-Management and e-Learning, 2(1), 22-27.

Paschal, R. A., Weinstein, T., \& Walberg, H. J. (1984). The effects of homework on learning: A quantitative synthesis. The Journal of Educational Research, 78(2), 97-104. http://dx.doi.org/10.1080/00220671.1984.10885581

Raines, J. M., \& Clark, L. M. (2013). Analyzing the effectiveness of tutorial learning aids in a course management system. Journal of Studies in Education, 3(3), 120-136. http://dx.doi.org/10.5296/jse.v3i3.4055

Speckler, M. D. (2012). Making the Grade, V.5: Data-driven Case Studies Illustrating How the MyMathLab Family of Products Supports Student Achievement. Boston, MA: Pearson.

Testone, S. (2005). Using publisher resources to assist developmental mathematics students. Research and Teaching in Developmental Education, 21(2), 81-84.

Vezmar, K. A. (2011). Analyzing the effects of MyMathLab on student achievement in elementary algebra (Doctoral dissertation). Available from ProQuest Dissertations and Theses database (UMI No. 3465766).

Walberg, H. J., Paschal, R. A., \& Weinstein, T. (1985). Homework's powerful effects on learning. Educational Leadership, 42(7), 76-79.

Zerr, R. (2007). A quantitative and qualitative analysis of the effectiveness of online homework in first-semester calculus. Journal of Computers in Mathematics and Science Teaching, 26(1), 55-73.

\section{Copyright Disclaimer}

Copyright for this article is retained by the author(s), with first publication rights granted to the journal.

This is an open-access article distributed under the terms and conditions of the Creative Commons Attribution license (http://creativecommons.org/licenses/by/3.0/). 